\title{
Investigation of Wettability of Lead Free-Solder on Bare Copper and Organic Solder Preservatives Surface Finishes
}

\author{
Gabriel Takyi $^{1}$, Peter Kojo Bernasko ${ }^{2}$ \\ ${ }^{1}$ Department of Mechanical Engineering, Kwame Nkrumah University of Science \& Technology, Kumasi, Ghana West Africa \\ ${ }^{2}$ Electronics Manufacturing Engineering Research Group, School of Engineering, University of Greenwich, Chatham Maritime, Kent, UK
}

Email address:

gtakyi.soe@knust.edu.gh (G. Takyi)

\section{To cite this article:}

Gabriel Takyi, Peter Kojo Bernasko. Investigation of Wettability of Lead Free-Solder on Bare Copper and Organic Solder Preservatives Surface Finishes. International Journal of Materials Science and Applications. Vol. 4, No. 3, 2015, pp. 165-172.

doi: $10.11648 /$ j.ijmsa.20150403.14

\begin{abstract}
Wettability plays an important role in the integrity of solder joints especially in critical safety operations. It helps in attaining successful soldering and reliable solder joints. The angle of wettability determines the degree of solder contact and strength of the solder joint. Moreover, the contact angle between the solid substrate and the molten solder determines the interconnection reliability. This paper focuses on the wettability of lead free solder on OSP and bare copper substrate surface finishes. The wetting behaviour of lead free solder pastes on bare copper board and Organic Solderability Preservatives (OSPs) substrates were investigated. The test vehicles consist of FR4 PCB single sided 100\% copper clad with a thick film metallization and FR4 PCB single sided OSP. The substrate dimension was $100 \mathrm{~mm} \times 160 \mathrm{~mm} \times 1.6 \mathrm{~mm}$. A total of $480 \mathrm{bumps}$ of Lead-free solder pastes $(96 \mathrm{Sn}-3.8 \mathrm{Ag}-0.5 \mathrm{Cu}$ and $96.5 \mathrm{Sn}-3.0 \mathrm{Ag}-0.7 \mathrm{Cu}$ alloy composition) were deposited for the investigation. The printing parameters and their values for the experiments include print gap of $0 \mathrm{~mm}$, squeegee speed of 20 $\mathrm{mm} / \mathrm{s}$, pressure of $8 \mathrm{~kg}$ and separation speed of $3 \mathrm{~mm} / \mathrm{sec}$. The pastes are screen printed on the substrates using $0.125 \mathrm{~mm}$ thick stencil mounted on DEK 260 series printing machine. After the stencil printing process, the solder bumps deposited on the substrates were reflowed using a Novostar 2000HT horizontal convention reflow oven with 4-stage (preheat-soak-reflowcooling). The FTA188 Analyser was employed for measuring the angle of contact between the substrates and the bumps. The results showed that the wetting contact angle of copper surface finish is lower as compared to the organic solderability preservatives surface finish and the wetting angle decreases as the contact surface area increases.
\end{abstract}

Keywords: Wettability, Solder Pastes, Surface Finish, Contact Angle

\section{Introduction}

The concept of wettability in various electronic assembly processes has influenced the quality and performance of several circuits in electronic products. An effective wetting can be determined depending on the alloy composition, flux, substrate and their interactions with one another. The wetting property between the solder and the substrate is crucial for the component reliability in electronic assembly $[1,2]$. In reference [3], it was stated that in the selection of a lead-free solder, the alloy should be readily available having a low melting temperature to reduce thermal damage, with good effective wetting behaviour on the base metal, and finally low cost should be considered. A study conducted in [4] shows that the formation of intermetallic can lead to good wetting on the substrate which is very important in the electronic assembly line as poor solder joints can bring about voids, resulting in weak joint. Reference [5] investigated the wetting behaviours and interfacial reactions of high temperature on $\mathrm{Sn}-10 \mathrm{Sb}-5 \mathrm{Cu}$ lead-free solder on a $\mathrm{Cu}$ substrate for electronic packages using differential thermal analysis (DTA) and 95Pb-Sn solder also on $\mathrm{Cu}$ substrate using atomic absorption spectroscopy (AAS) to evaluate the wetting behaviour. The findings indicated that the wetting behaviour of $\mathrm{Sn}-10 \mathrm{Sb}-5 \mathrm{Cu}$ lead-free solder was more superior to that of $95 \mathrm{~Pb}-\mathrm{Sn}$ solder in terms of maximum wetting force, wetting time and wetting angle, for a temperature range of between $340-400^{\circ} \mathrm{C}$. Reference [4] investigated the wetting behaviour of $\mathrm{Sn}-\mathrm{Bi}-\mathrm{Cu}$ lead-free solder on a $\mathrm{Cu}$ substrate using the sessile drop method in an Ar-H2 flow. The study established that the contact angle curve tested at $548 \mathrm{~K}$ and $623 \mathrm{~K}$ met the exponential rule than when temperature was below $493 \mathrm{~K}$. The finding 
indicated that $69.5 \mathrm{Sn}-30 \mathrm{Bi}-0.5 \mathrm{Cu}$ exhibits good wettability when $\mathrm{Cu}$ substrate is used for printing. According to [6], an excellent wettability is obtained using $\mathrm{Sn}-9 \mathrm{Zn}-0.5 \mathrm{Ag}$ solder with Ag-precoated $\mathrm{Cu}$ substrate than $\mathrm{Cu}$ substrate. The researchers concluded that the sessile drop method has to do with the surface energy of the alloy in order to achieve good wettability. Investigation on wettability of In-Sn, Au-Sn and $\mathrm{Cu}-\mathrm{Sn}$ using $\mathrm{Cu}$ and $\mathrm{Ni}$ substrates was conducted and reported in [7]. It was found that $\mathrm{Cu}-\mathrm{Sn}$ showed better wettability on the $\mathrm{Cu}$ substrate than $\mathrm{Ni}$ at low temperature. The workers concluded that the presence of alloying elements such as $\mathrm{In}, \mathrm{Cu}$ and $\mathrm{Au}$ does not influence the wettability using $\mathrm{Ni}$ and $\mathrm{Cu}$ substrates. Research work was carried out on wettability behaviour using hypoeutectic Sn$\mathrm{Zn}$ lead-free alloy on $\mathrm{Cu}$ substrate for electronic assembly under lower temperature and reported in [8]. It was found that $\mathrm{Sn}-6.5 \mathrm{Zn}$ was better than $\mathrm{Sn}-9 \mathrm{Zn}$ in terms of wettability. Furthermore, [9] stated that alloy impurities have negative impact on wettability of Sn-based metals. However, much research has not been conducted on wettability of OSP and $\mathrm{Cu}$ substrates before and after reflow soldering, given the opportunity to establish the behaviour of wettability before and after reflow soldering.

\section{Experimental Procedure}

\subsection{Material Preparation}

The test vehicles used for the investigation of wettability of two different substrates are represented in figures 1 and 2 .
The test substrates of figures 1 and 2 consist of Organic Solderability Preservatives (OSP) and bare copper $(\mathrm{Cu})$ respectively. Four different areas were demarcated on each substrate for investigation as wetting area A, B, C and D as shown in table 1 . The area of each solder pad in the region designated as wetting A (area between pads 1,2,3,4,5 and 6) were the same $(0.83 \mathrm{~mm} 2)$. Wetting $\mathrm{B}, \mathrm{C}$ and $\mathrm{D}$ pads areas on the other hand vary as shown in table 1 . This is due to the design of the stencil. Wetting $\mathrm{B}$ for example has pad areas changing from $1.99 \mathrm{~mm} 2,0.44 \mathrm{~mm} 2$ to $0.04 \mathrm{~mm} 2$ (area between pads 7,8,9,10,11 and 12). Forty eight (48) substrates were used in this study consisting of 480 bumps. The solder pastes used for printing on a DEK 260 stencil printer includes; 96.5 Sn-3.0Ag-0.7Cu and $96.5 \mathrm{Sn}-3.8 \mathrm{Ag}-0.5 \mathrm{Cu}$. The printing process parameters used include a pressure of $8 \mathrm{~kg}$, separation speed of $100 \%$, speed of $50 \mathrm{~mm} / \mathrm{s}$ and snap off of $0 \mathrm{~mm}$. The substrates with 480 solder bumps were reflowed using Novostar 2000HT Horizontal Convention Reflow Oven with a 4-stage preheat-soak-reflow-cooling. The temperature profile used for all the samples include: preheat at $180^{\circ} \mathrm{C}$ for $60 \mathrm{sec}$, soak temperature at $180{ }^{\circ} \mathrm{C}$ for $180 \mathrm{sec}$, reflow temperature at $230^{\circ} \mathrm{C}$ to 241 for 120 seconds and cooling at $180^{\circ} \mathrm{C}$ to $1000 \mathrm{C}$ for $90 \mathrm{sec}$ and unloaded to cool at $250 \mathrm{C}$ ambient for further processing as shown in figure 3.The solder bumps were subjected to shear test using Dage4000PXY Bond tester (figure 4) with test speed of $700 \mu \mathrm{m} / \mathrm{s}$, maximum shear distance of $3,000 \mu \mathrm{m}$, a test load of 196.10 $\mathrm{N}$, shear height of $100 \mu \mathrm{m}$ and a land speed of $500 \mu \mathrm{m} / \mathrm{s}$.

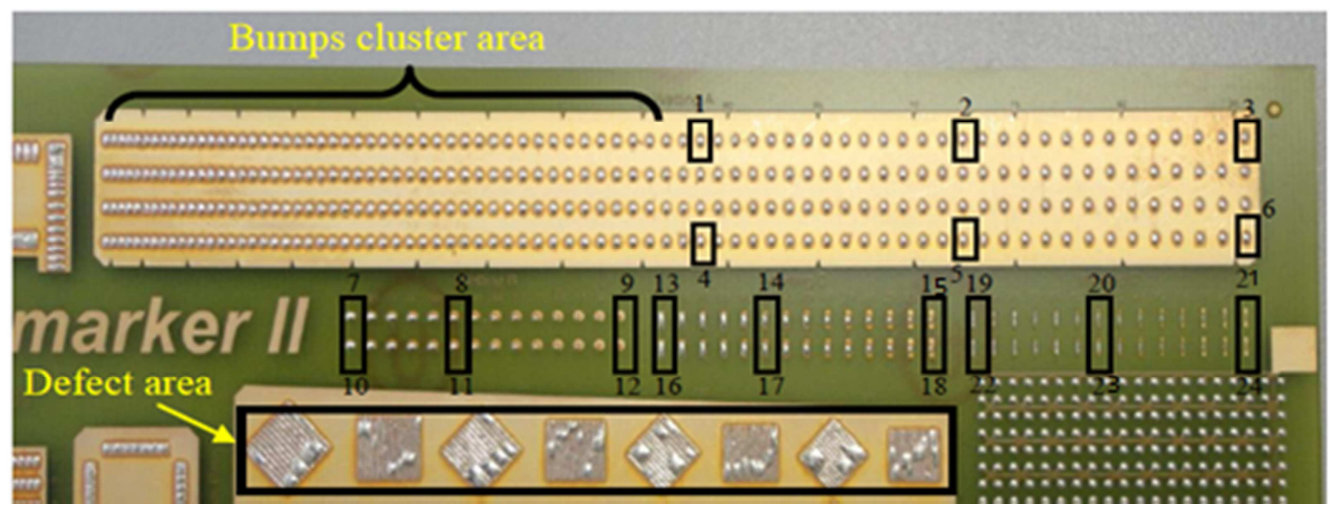

Figure 1. Reflowed solder bumps on OSP surface finish.

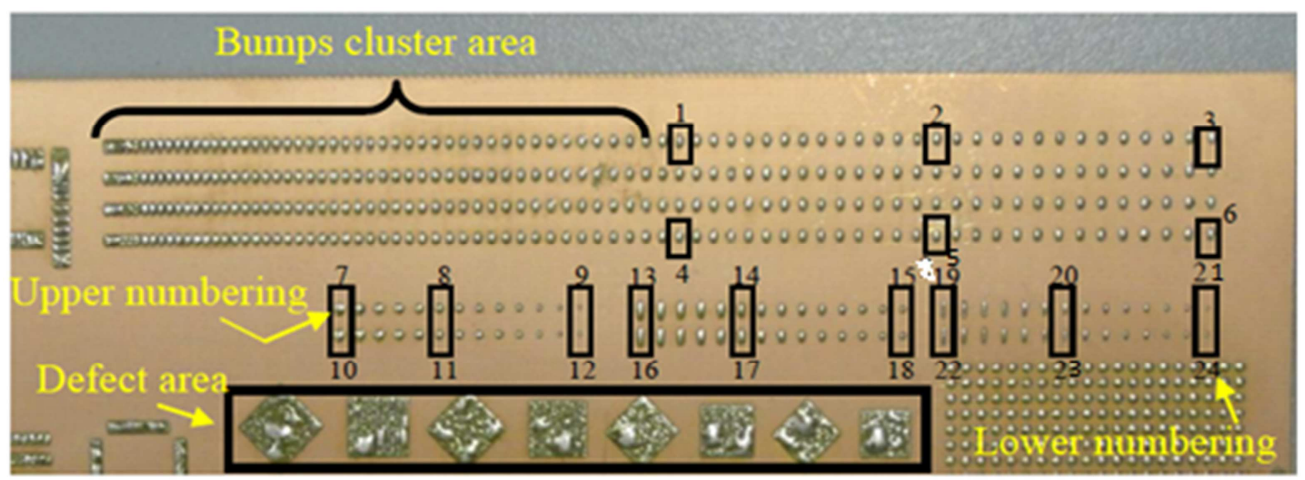

Figure 2. Reflowed solder bumps on bare copper. 
Table 1. Areas selected for investigation.

\begin{tabular}{|c|c|c|c|c|c|}
\hline \multicolumn{6}{|c|}{ OSP SURFACE FINISH AND BARE COPPER BOARD } \\
\hline $\mathbf{S} / \mathbf{N}$ & Wetting ty & number & Area of stencil $\left(\mathrm{mm}^{2}\right)$ & QTY & SIZE \\
\hline 1 & \multirow{3}{*}{ Wetting A } & 1,4 & 0.83 & \multirow{12}{*}{20} & \multirow{12}{*}{$\begin{array}{l}190 \mathrm{~mm} \\
\mathrm{x} \\
127 \mathrm{~mm} \\
\mathrm{x} \\
1.5 \mathrm{~mm}\end{array}$} \\
\hline 2 & & 2,5 & 0.83 & & \\
\hline 3 & & 3,6 & 0.83 & & \\
\hline 4 & \multirow{3}{*}{ Wetting B } & 7,10 & 1.19 & & \\
\hline 5 & & 8,11 & 0.55 & & \\
\hline 6 & & 9,12 & 0.04 & & \\
\hline 7 & \multirow{3}{*}{ Wetting C } & 14,17 & 1.88 & & \\
\hline 8 & & 13,16 & 1.33 & & \\
\hline 9 & & 15,18 & 0.34 & & \\
\hline 10 & \multirow{3}{*}{ Wetting D } & 19,22 & 0.54 & & \\
\hline 11 & & 20,23 & 0.39 & & \\
\hline 12 & & 21,24 & 0.13 & & \\
\hline
\end{tabular}

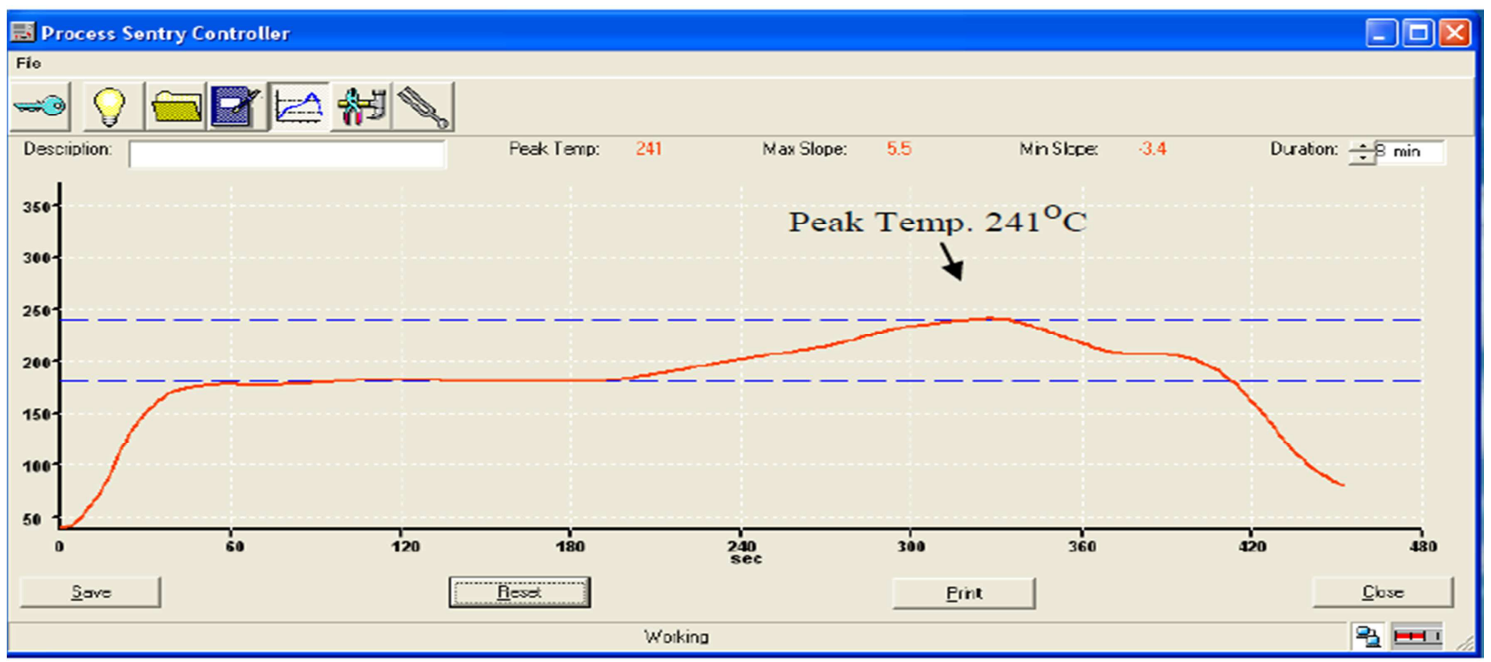

Figure 3. Reflow soldering profile.

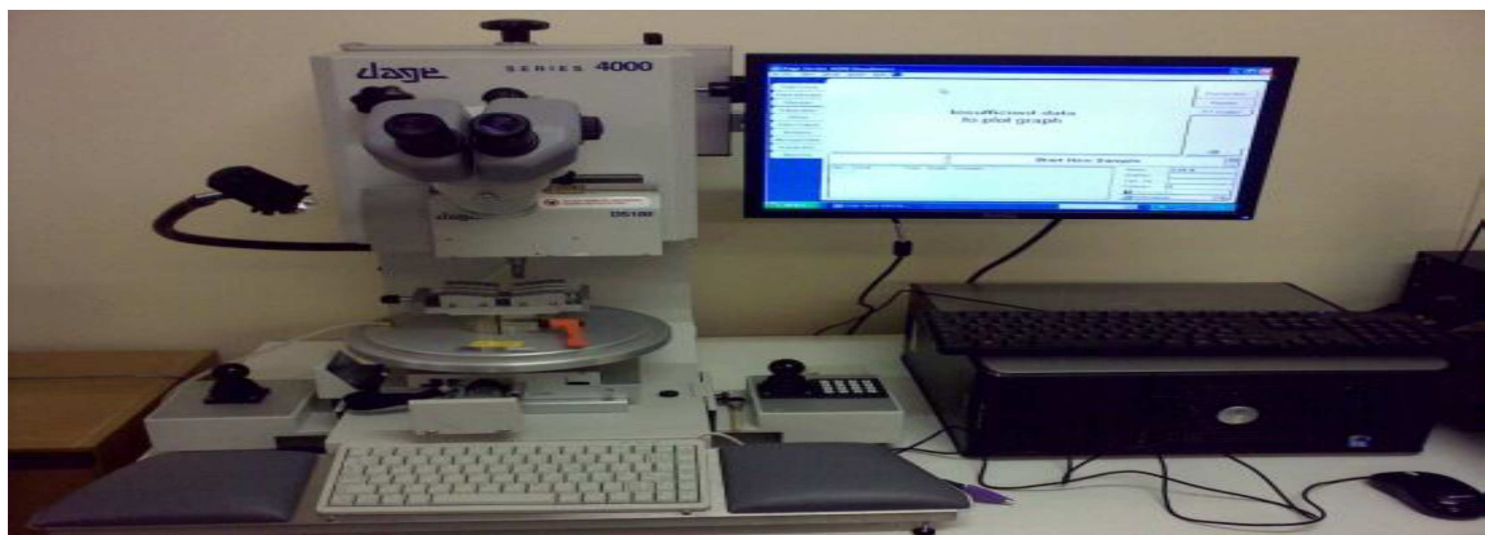

Figure 4. Dage Bond Tester-4000PXY.

\subsection{Method}

The Analyzer FTA188 series as shown in figure 5 was used to measure the contact. The drop shape technique was employed to measure the contact angle of the reflowed solder bumps. The brightness and contrast of the Analyzer was set to 60 percent so that the silhouette to get enough light density on the solder bumps for measurement to reduce error can be achieved and also to improve accuracy of the captured video image of the 480 bumps recorded. Important parameters equally considered include; magnification of image focus, optimum size of the solder bump and bump screen filling. The contact angle analyzer is placed parallel to the bumps under investigation. The baseline of each of the bump is indicated with the assistance of the inbuilt zoom to locate the start and finish points of the bump contact on the substrate. The contact angle analyzer uses software Fta32 Video 2.0 which helps both automatic and manual settings. It enables 
the viewing of the silhouette image with appropriate lighting system and a dialogue box of recorded parameter values.
Figure 6 shows a screen displaying the results of contact angle analysis using the FAT 32 software.

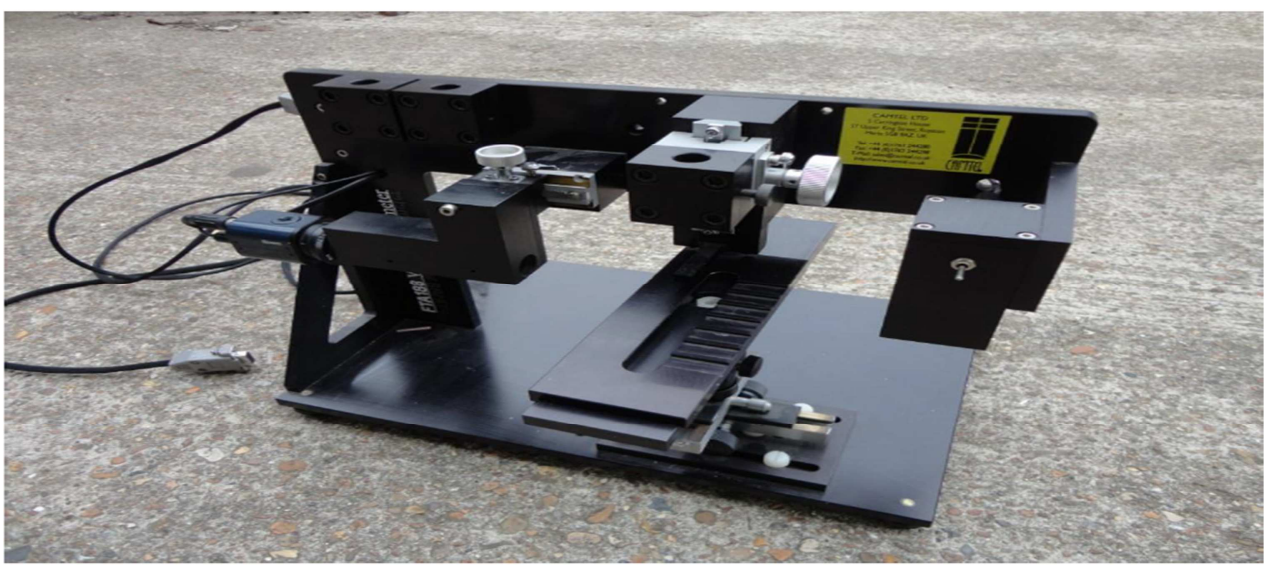

Figure 5. Analyzer FTA188 series.

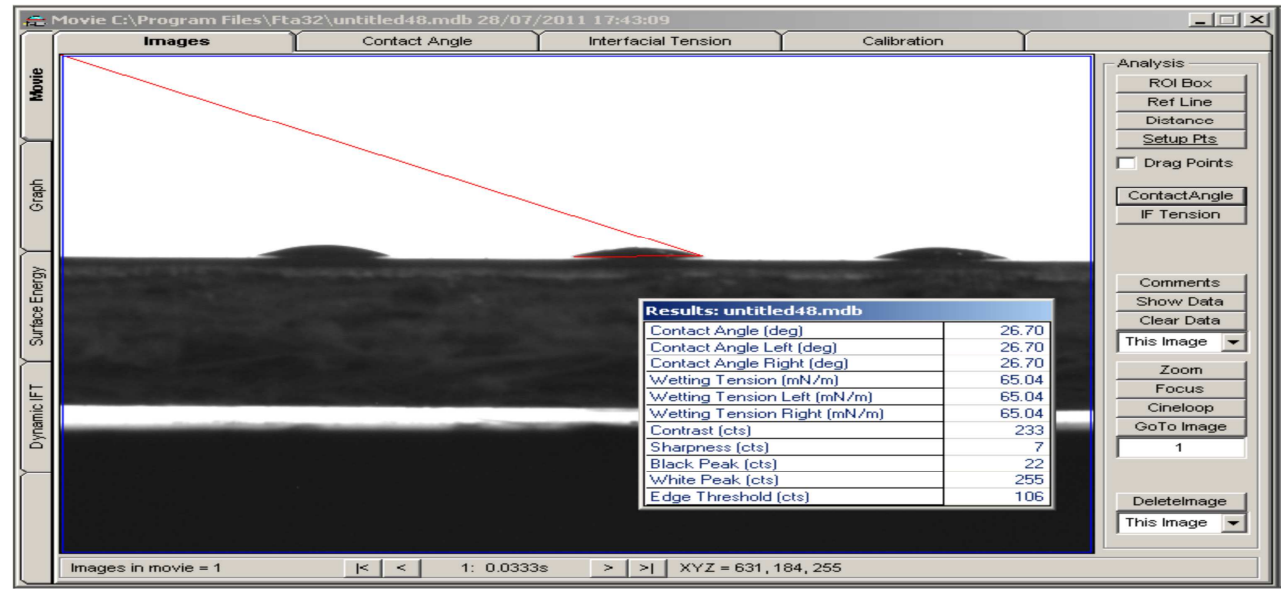

Figure 6. Contact angle result on FTA32 Video 2.0 software analysis.

\section{Results and Discussion}

\subsection{Wettability Behaviour of OSP Surface Finish of 96.5Sn-3.0 Ag-0.7 $\mathrm{Cu}$ and 96.5Sn-3.8Ag-0.5Cu}

Figures 7 and 8 show the results of the wettability of 96.5 Sn-3.0Ag-0.7 Cu and $96.5 \mathrm{Sn}-3.8 \mathrm{Ag}-0.5 \mathrm{Cu}$ solder pastes on OSP respectively. The average contact angles for $96.5 \mathrm{Sn}-$
3.0Ag-0.7Cu wetting areas A, B, C and D are 20, 22, 34 and 40 degrees respectively. Nevertheless, contact angles of $96.5 \mathrm{Sn}-3.8 \mathrm{Ag}-0.5 \mathrm{Cu}$ for the same wetting areas include; 30 , 25, 30 and 34 degrees. In both cases, in terms of the solder pastes the wetting tension (or surface tension) is similar except wetting area $\mathrm{D}$. The results indicate that the lower the contact angle the higher the wetting tension and the more wettable the surface.

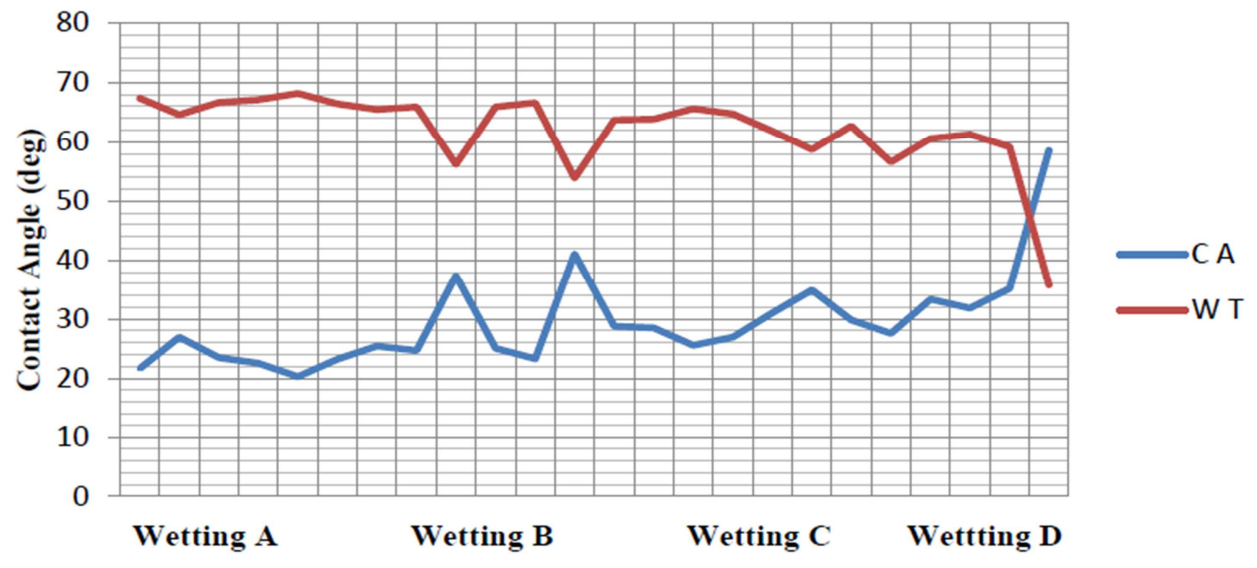

Figure 7. Wetting tension and contact angle of 96.5Sn-3.0Ag-0.7Cu of OSP. 


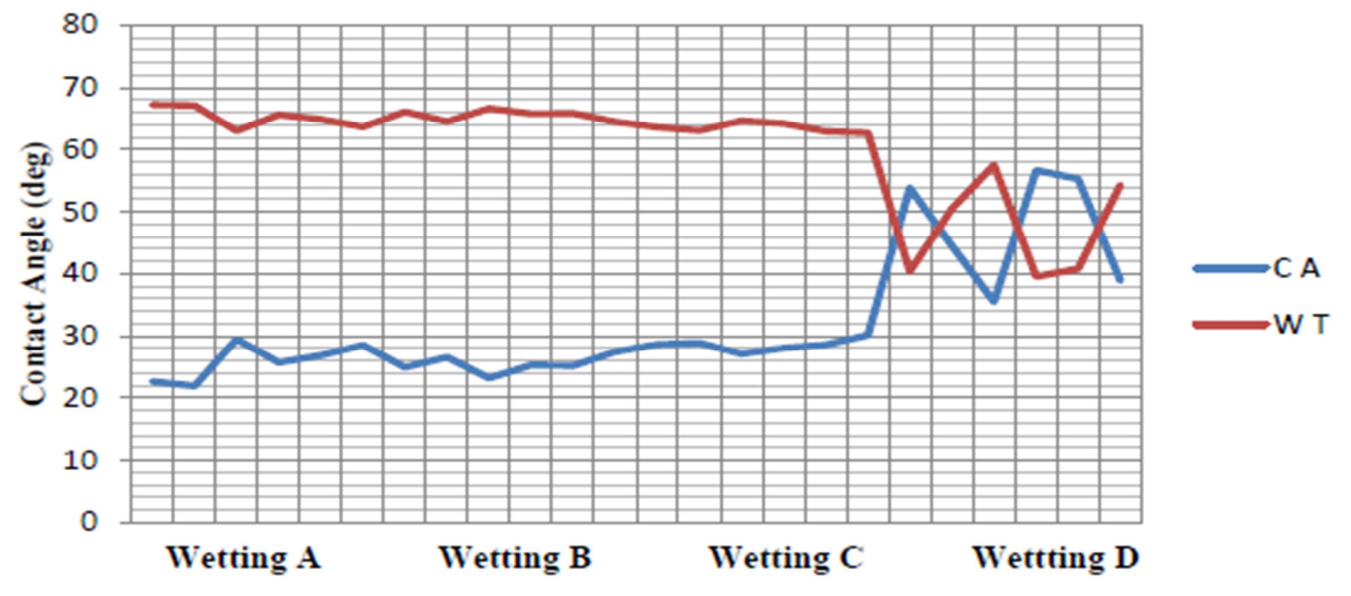

Figure 8. Wetting tension and contact angle of $96.5 \mathrm{Sn}-3.8 \mathrm{Ag}-0.5 \mathrm{Cu} \mathrm{OSP}$.

\subsection{Behaviour 96.5-3.0 Ag-0.7Cu and 96.5Sn-3.8Ag-0.5Cu bumps on OSP with Different Areas}

Figure 9 (96.5Sn-3.0Ag-0.7Cu solder paste on OSP surface finish) shows the smallest wetting areas $0.04 \mathrm{~mm} 2$ and $0.13 \mathrm{~mm} 2$ recording the highest contact angles of 39 and 46 degrees respectively. This behaviour may be due to the small area size restricting the melting of the solder paste during reflow.

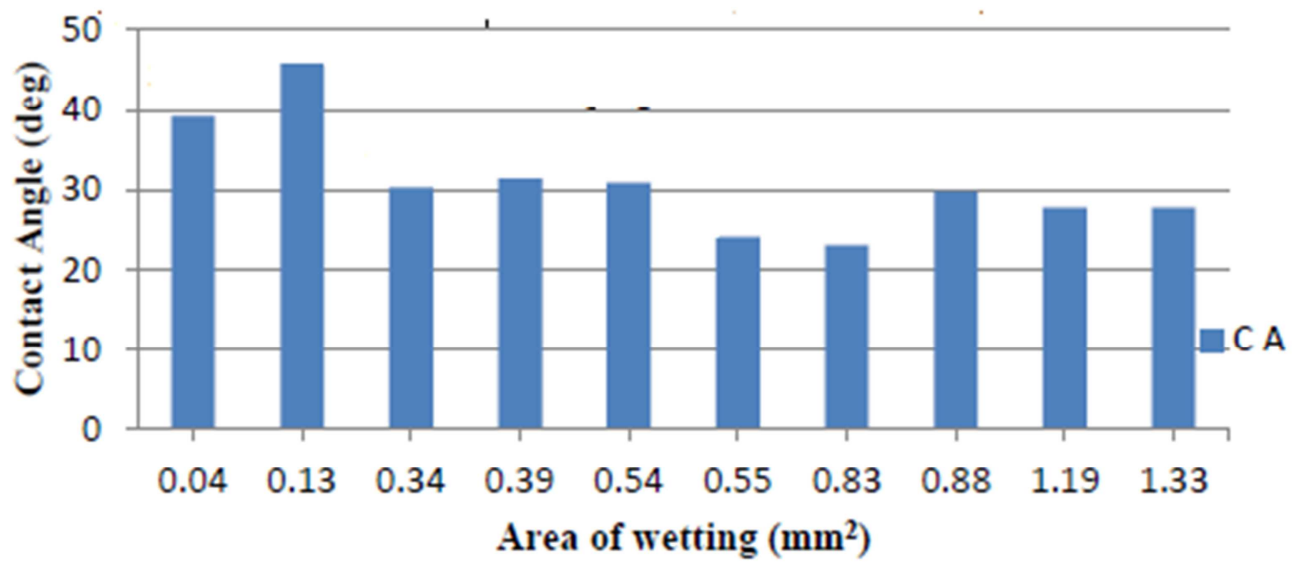

Figure 9. Behaviour of 96.5Sn-3.0Ag-0.7Cu bumps on OSP with different areas.

Figure 10 shows the results of the behaviour of $96.5 \mathrm{Sn}$ $3.8 \mathrm{Ag}-0.5 \mathrm{Cu}$ solder bumps on the OSP surface finish. The results show higher contact angles again recorded for the lower areas with $0.13,0.39$ and 0.54 recording the highest.
The poor contact angles obtained from $0.39 \mathrm{~mm} 2$ and 0.54 $\mathrm{mm} 2$ wetting areas might be due to oxidization and the solder paste pressure.

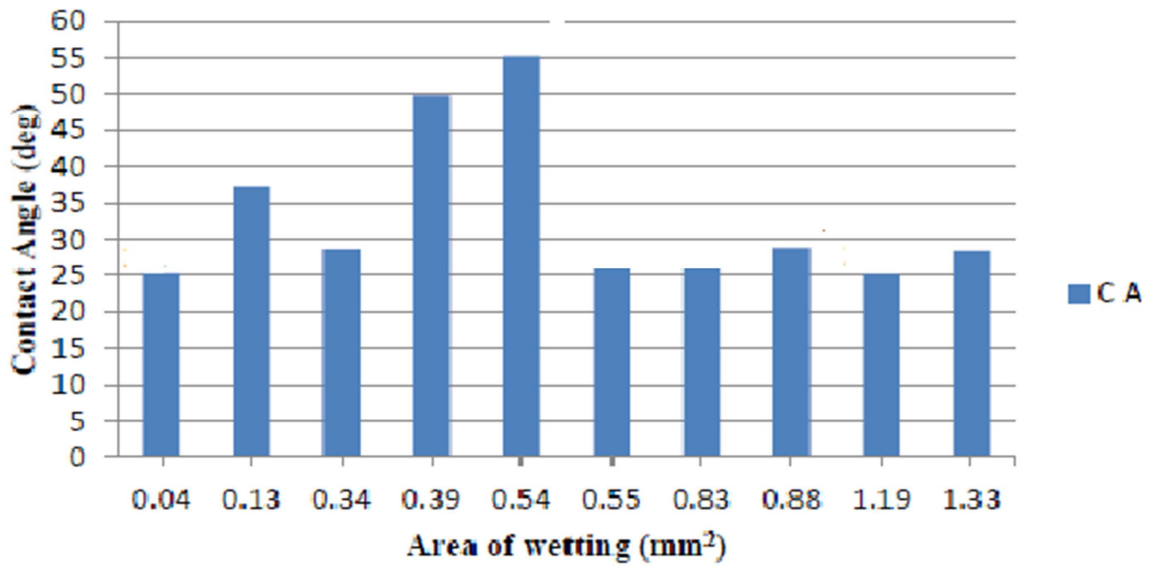

Figure 10. Behaviour of $96.5 \mathrm{Sn}-3.8 \mathrm{Ag}-0.5 \mathrm{Cu}$ bumps on OSP with different areas. 


\subsection{Wettability Behaviour of Bare Cu Surface Finish of 96.5Sn-3.0 Ag-0.7Cu and 96.5Sn-3.8Ag-0.5Cu}

The solder wettability using $96.5 \mathrm{Sn}-3.0 \mathrm{Ag}-0.7 \mathrm{Cu}$ on 0.54 $\mathrm{mm} 2,0.83 \mathrm{~mm} 2,1.19 \mathrm{~mm} 2$, and $1.33 \mathrm{~mm} 2$ pad sizes were 22 , 20,30 and 26 degrees. The wetting tensions of $1.33 \mathrm{~mm} 2$ and $0.54 \mathrm{~mm} 2$ were similar except for $0.83 \mathrm{~mm} 2$ and $1.19 \mathrm{~mm} 2$ areas where wetting tensions were slightly high as shown in figure 11. Figure 12 shows the average contact angle and wetting tension measured using $96.5 \mathrm{Sn}-3.8 \mathrm{Ag}-0.5 \mathrm{Cu}$ solder paste. The average contact angle of wetting area $0.83 \mathrm{~mm} 2$ was $26^{\circ}$. There was not much difference in the contact angles measured for areas $1.33 \mathrm{~mm} 2,1.193 \mathrm{~mm} 2$ and $0.54 \mathrm{~mm} 2$. The difference in wetting tensions measured at these four areas is $5 \%$.

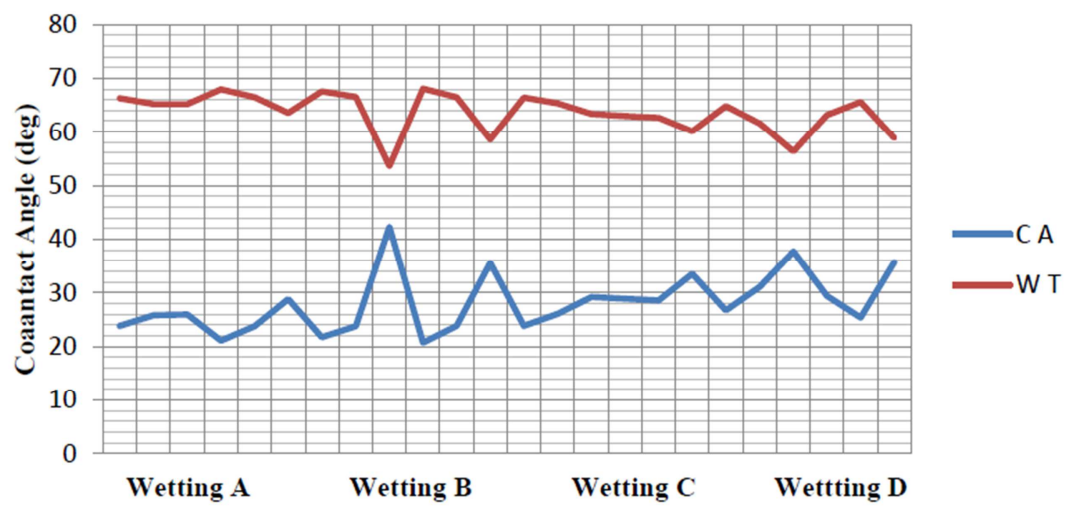

Figure 11. Wetting tension and contact angle of $96.5 \mathrm{Sn}-3.0 \mathrm{Ag}-0.7 \mathrm{Cu}$ of bare copper.

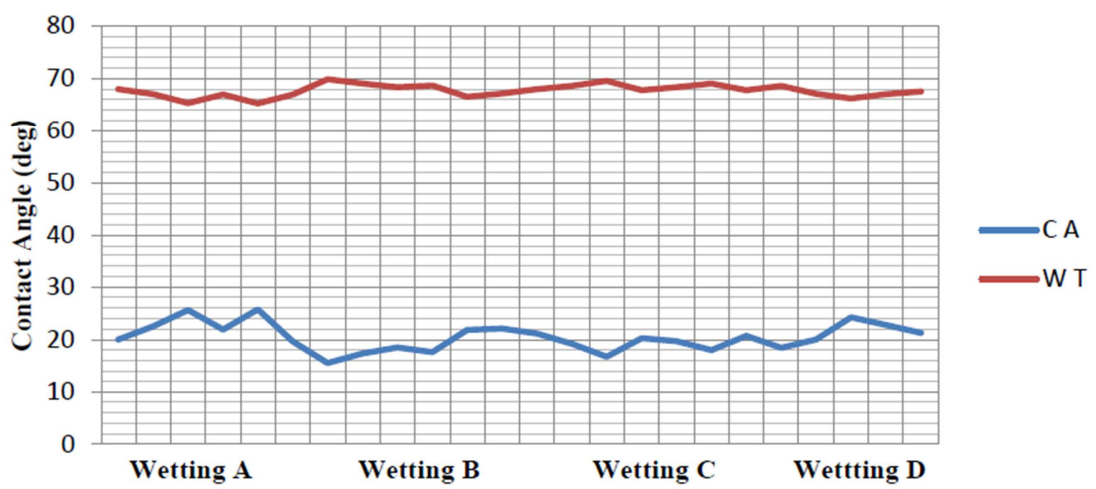

Figure 12. Wetting tension and contact angle of $96.5 \mathrm{Sn}-3.8 \mathrm{Ag}-0.5 \mathrm{Cu}$ of bare copper.

\subsection{Wettability Behaviour 96.5-3.0 Ag-0.7Cu and 96.5Sn- 3.8Ag-0.5Cubumps on Bare Copper with Different Areas}

Figure 13 shows the wetting behaviour of $96.5 \mathrm{Sn}-3.0 \mathrm{Ag}$ $0.7 \mathrm{Cu}$ on a bare copper board of areas from $(0.04-1.33)$ $\mathrm{mm} 2$. It was observed that there was a decrease in contact angle as the area increases. This may be attributed to the wider contact area. There was a slight increase in contact angle at areas $0.88 \mathrm{~mm} 2$ and $1.33 \mathrm{~mm} 2$. This may be due to poor contact due to oxidization.

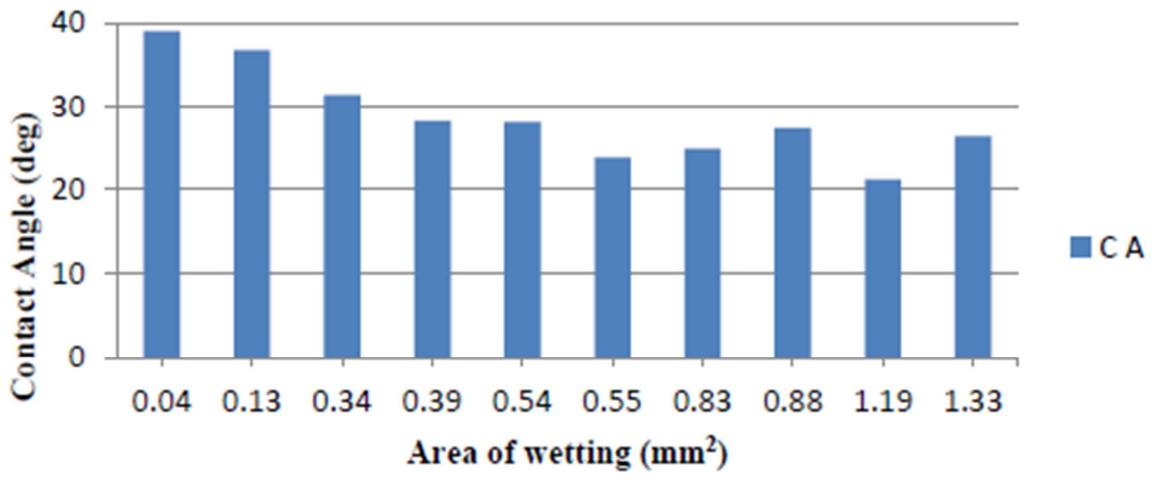

Figure 13. Behaviour 96.5Sn-3.0Ag-0.7Cu bumps on bare copper with different areas. 
Figure 14 shows different behaviour of 96.5Sn-3.8Ag$0.5 \mathrm{Cu}$ with respect to the wetting behaviour. The results show that contact angles at smaller wetting areas were almost the same as those of larger areas. This might be due to faster melting of the solder deposit during the reflow soldering process which is consistent with that reported in [10]. There was also an inconsistent variation in the contact angles measured as the wetting area increases. This effect could be attributed to the degree of oxidization.

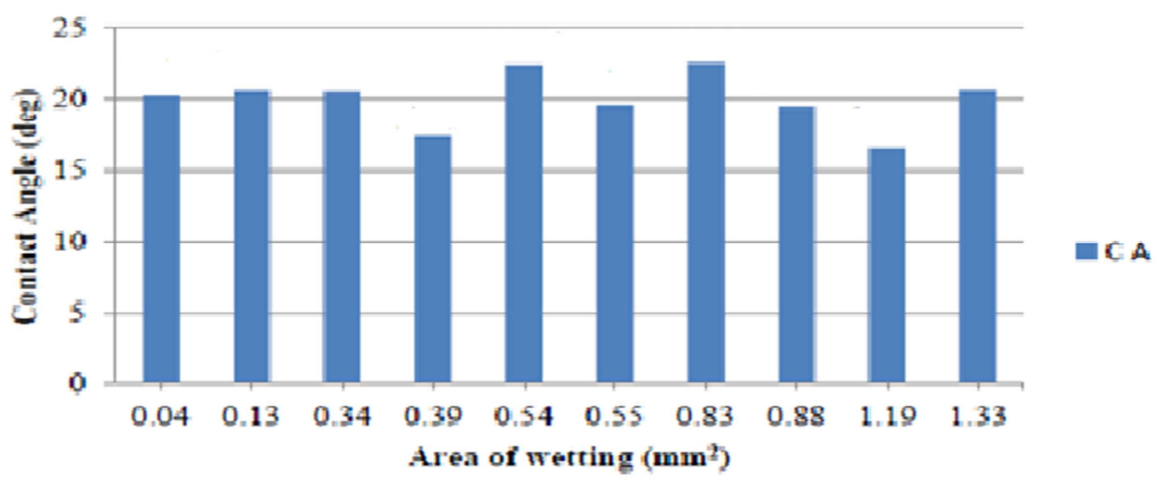

Figure 14. Behaviour of 96.5Sn-3.8Ag-0.5Cu bumps on bare copper with different areas.

Figure 15 shows the behaviour of OSP and bare copper of 96.5 Sn-3.0Ag-0.7 Cu and $96.5 \mathrm{Sn}-3.8 \mathrm{Ag}-0.5 \mathrm{Cu}$. The results show that bare copper and $96.5 \mathrm{Sn}-3.8 \mathrm{Ag}-0.5 \mathrm{Cu}$ (type 7) exhibited good wettability contact angles. The difference in the contact angle is negligible. The bare copper and $96.5 \mathrm{Sn}$ 3.0Ag- $0.7 \mathrm{Cu}$ (type 3 ) actually exhibited contact angle of $40^{\circ}$ at $0.04 \mathrm{~mm} 2$, the wettability improved as the area increased which could be attributed to the decrease in oxide layer of bare copper. Similar values were obtained using OSP and 96.5 Sn-3.0Ag-0.7 Cu (type 7). At $0.04 \mathrm{~mm} 2$ the contact angle measured was 40 degrees whiles the contact angle improved as the area increases. The results of OSP and 96.5Sn-3.8Ag$0.5 \mathrm{Cu}$ solder paste (type 3 ) shows that poor wettability of 50 degree at $0.3 \mathrm{~mm} 2$ was due to impurities of the contact area. There was a decrease in contact angles due to increase in contact area.

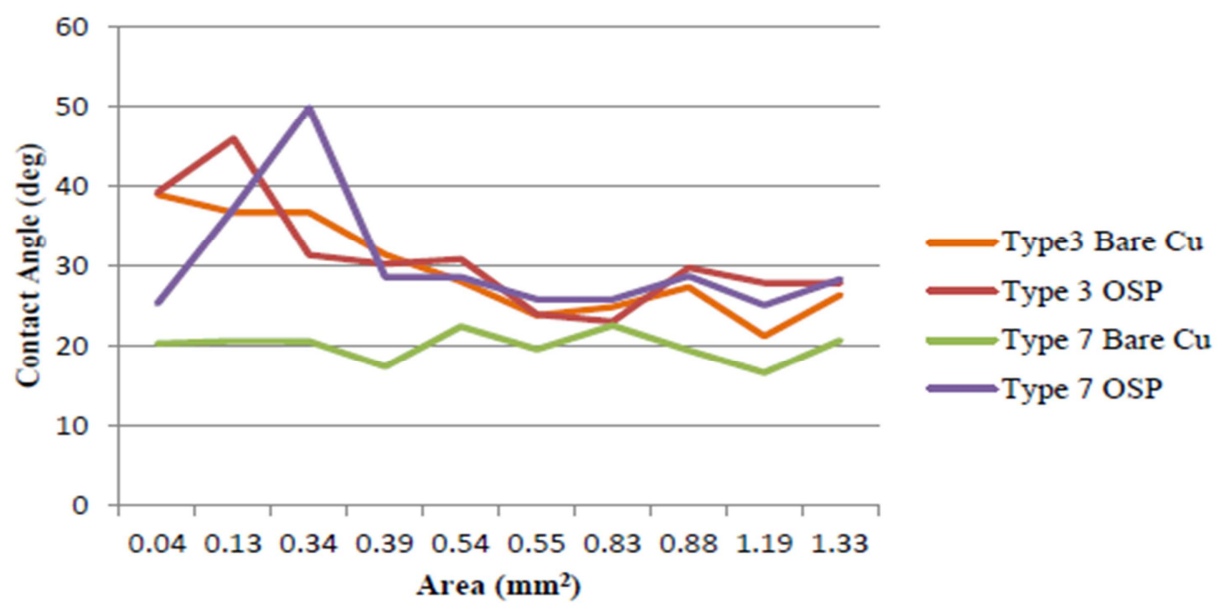

Figure 15. OSP and copper bare effect on 96.5Sn-0.3Ag-0.7Cu and 96.5Sn-3.8Ag-0.5Cu solder pastes.

\section{Conclusion}

In this study, the influence of OSP and bare Copper surface finishes using $96.5 \mathrm{Sn}-3.0 \mathrm{Ag}-0.7 \mathrm{Cu}$ and $96.5 \mathrm{Sn}-3.8 \mathrm{Ag}-0.5 \mathrm{Cu}$ solder pastes on wettability have been evaluated. Relatively low contact angles were obtained using $96.5 \mathrm{Sn}-3.8 \mathrm{Ag}-0.5 \mathrm{Cu}$ solder paste on bare copper board indicating better solder wettability. Slightly high contact angles were obtained using 96.5Sn-3.8Ag-0.5Cu and OSP. The 96.5Sn-3.0Ag-0.7Cu solder paste on bare copper board exhibited contact angle of 40 degrees at a small area of $0.04 \mathrm{~mm} 2$. The wettability improved as the area increased. A contact angle of 20 degrees was obtained when $96.5 \mathrm{Sn}-3.0 \mathrm{Ag}-0.7 \mathrm{Cu}$ solder paste was used on bare copper board at a larger area of $1.19 \mathrm{~mm} 2$. Similar results were obtained with $96.5 \mathrm{Sn}-3.8 \mathrm{Ag}-0.5 \mathrm{Cu}$ and OSP. The results generally indicate that the larger the surface area the more wettable the surface.

\section{Acknowledgement}

The authors would like to acknowledge the assistance provided by staff and researchers of EMERG, University of Greenwich for the work reported in this article. 


\section{References}

[1] Fu, Chun-Chong and Che, Chih-chi., 2011, Investigations of wetting properties of $\mathrm{Ni}-\mathrm{V}$ and $\mathrm{Ni}-\mathrm{Co}$ alloys by $\mathrm{Sn}, \mathrm{Sn}-\mathrm{Pb}, \mathrm{Sn}-$ $\mathrm{Cu}$ and $\mathrm{Sn}-\mathrm{Ag}-\mathrm{Cu}$ solders, Journal of the Taiwan Institute of Chemical Engineers, 42, pp.350-355.

[2] Passerone, A., Ricci, E., R. Sangiogi, R., J, 1990, Effect of metal purity and testing procedure on surface tension measurements of liquid tin, Material Sci. 25, 4266.

[3] Wu, C. M. L., Yu, D. Q., Law, C. M. T. and Wang, L., 2004, Properties of lead-free solder alloys with rare earth element additions. Materials Science and Engineering, R 44. Pp.1-44.

[4] Zang, L., Yuan, Z., Zhao, H. and Zhang, X., 2009, Wettability of molten $\mathrm{Sn}-\mathrm{Bi}-\mathrm{Cu}$ solder on $\mathrm{Cu}$ substrate, Material Letters, 63, pp.2067-2069.

[5] Zeng, Q., Guo, J., Gu, X., Zhao, X. and Liu, X., 2010, Wetting Behaviours and Interfacial Reaction between Sn-10Sb-5Cu High Temperature Lead-Free Solder and $\mathrm{Cu}$ Substrate. Journal of Materials Science and Technology, 26(2), pp.156-162
[6] Chang, T., Hsu, Y., M., Wang, M., 2003, Enhancement of wettability and solder joint reliability at the Sn-9Zn-0.5Ag Lead-free solder alloy-Cu interface by Ag precoating, Journal of Alloys and Compounds 360, pp.217-224.

[7] Amore, S., Ricci, E., Borzone, G. and Novakovic, R., 2008, Wetting behaviour of lead-free $\mathrm{Sn}$-based alloys on $\mathrm{Cu}$ and $\mathrm{Ni}$ substrates, Material Science and Engineering, A 495, pp.108112.

[8] Wei, X., Huizhen H., Zhou, L., Zhang, M. and Liu, X., 2007, On the advantages of using a hypoeutectic $\mathrm{Sn}-\mathrm{Zn}$ as lead-free solder material, Materials letters. 61. pp.655-658.

[9] Laurila, T., Vuorinen, V., Paulasto-Krockel, M., 2010, Impurity and alloying effects on interfacial reaction layers in $\mathrm{Pb}$-free soldering, Material Science and Engineering, R 68, pp.138.

[10] Sobczak, N., Kudya, A., Nowak, R., Radziwill, W., Pietrzak, K., 2007, Factors affecting wettability and bond strength of solder joint couples, Pure Appl. Chem., Vol. 79, N0. 10, pp. 1755-1769. 